\title{
THE FALLACIES OF MDA FOR NOVICE DESIGNERS: OVERUSING MECHANICS AND NEGLECTING AESTHETICS
}

\author{
Kenneth Chen \\ Drexel University, 3501 Market Street, Philadelphia, PA, 19104, USA
}

\begin{abstract}
Ever since MDA was publicized by Hunicke et al. in 2004, it has become a building block for game developers and scholars. However, it has also incited several misconceptions that have spread among students and the gaming community. For example, players have overused the term "mechanics," to the point that it is virtually meaningless. On the other side, the terms "dynamics" and "aesthetics" have been comparatively neglected, despite their value. Building upon my experiences of teaching an undergraduate game design course, I argue that these misconceptions stem from the ways that consumers have misinterpreted the MDA framework. Game educators are not necessarily working with experienced designers: they are working with students who are often more passionate about playing games than making them. Thus, game educators need to target this misconception in order to shed light on preconceived biases.
\end{abstract}

\section{KEYWORDS}

Game Design, Teaching, Mechanics, Dynamics, Aesthetics

\section{INTRODUCTION}

With the rise of game development as a viable career choice, more and more students are entering game design programs for higher education. Decades ago, potential designers were seen as solitary tinkerers, but now, they are players who feel inspired by games and have paths to turn that inspiration into production. However, this introduces a new problem: these players often develop misconceptions about game design based on their experiences from consuming games rather than creating them. On the academic level, instructors need to be aware of these misconceptions and specifically target them.

The misconception I want to discuss is the concept of mechanics. This word was popularized by Hunicke et al. in a 2004 workshop paper at GDC, along with dynamics and aesthetics in their foundational MDA model (Hunicke et al, 2004). MDA argues that game design can be understood as the connections among mechanics (data, formulas, rules), dynamics (behaviors, interactions, decisions), and aesthetics (emotions, reactions, feelings). Since its inception, MDA has been appropriated by players and morphed into an amalgamation of different definitions. In its current state, the word "mechanics" is nearly meaningless, and has lost all of its insight into the MDA framework. Despite this, the word is still extremely common not only among players, but also among students who are relying on their previous experience as players.

For instructors in game development, it is not sufficient to teach students how to make games. They also need to unteach students how they thought games were supposed to be made. Many of the students who are entering university-level game design programs are primarily inspired by playing games rather than making games. Even though MDA was originally developed as a means to bridge this divide, I argue that it has unintentionally yet ironically widened it. However, if we become more aware of the problem, we can take steps to fix the situation.

\section{THE GAP BETWEEN DEFINITIONS}

Some of the more experienced and established members of the industry and academic communities might not be familiar with the ways in which the gaming community has twisted the word "mechanics." Although there isn't exactly a true dictionary definition, players have generally taken the term to mean something along the lines of the expression of skillful play through controlled intentional inputs. This is often paired with a positive connotation. 
In some online gaming communities, mechanics are considered as an element of skill, separated from tactics or communication or foresight. Thus, mechanics in this sense become more closely related to reflexes or precision in timing and aiming. For example, the following quote refers to a player's reaction to the boss monster Kushala Daora in Monster Hunter World:

"Technically among the worst designed enemies in the history of video games. Design and executionwise obviously. Really*****ty and meaningless enemy design; sloppy hitboxes and stagger. This is how you literally ruin a mechanical game and turn it into a cheese/equipment fest." - Anonymous

This quote from a gaming wiki forum illustrates a different use of "mechanics" than the one seen before in the player analysis. We can reinterpret this passage to mean that the stifling of player skill is an indication of poor design.

And yet, that is false, because the stifling of player skill is an important part of a game designer's toolbox. Perhaps the designer has decided that this is the point at which players should stop trying to muscle their way through a fight with quick reflexes, but rather take a more deliberate and methodical approach. Many game design principles discuss the idea of increasing difficulty over time and forcing players to develop new skills to approach new problems. This is the core concept of psychological flow (Chen, 2006) and the reason why learning is fun (Koster, 2003). The player has used the concept of mechanics in terms of skill in order to discuss the concept of mechanics in terms of design. Since these two concepts are different, the player fails to realize some of the most basic principles of game design.

Clearly, the player is just frustrated and most likely not actually trying to conduct an insightful design analysis. This is just an exaggerated example of the overreaching mentality that I want to expose. When students emphasize the importance of mechanics as a skill, they fail to recognize the larger design implications behind these decisions. Even though both players and designers are saying "mechanics," they are not communicating the same meaning. If this anonymous player were a college-bound game design major, we as educators cannot teach them the formal definition of a mechanic until we first address their misconception of that definition.

Moving away from the game consumer community, the game development community also suffers from the ambiguity circling the word "mechanics." We can see an especially odd use of this term in Martin Sahlin's GDC 2017 talk "Unravel - Using Empathy as a Game Mechanic" (Sahlin, 2017):

"Unravel turned empathy into a game mechanic. I wanted players to fall in love... Then break their hearts! Then we make it all worth it." - Martin Sahlin

While these are certainly interesting and valuable goals for a game designer, the use of the word "mechanic" just invites even more confusion. Moreover, this is a point at which the term "aesthetics" from the original framework would have been perfectly appropriate. It is doubtful that Sahlin was unaware of the MDA framework. The word "mechanic" just communicated the point better, because the word has expanded to mean practically any part of a game.

When Sahlin uses the term "mechanics" instead of the more appropriate term "aesthetics," he reflects a similar shift in public perception. People are putting less emphasis on dynamics/aesthetics and more emphasis on mechanics, and then expanding the definition of mechanics to include dynamics/aesthetics. The whole purpose of MDA was to separate these three concepts so that designers could intelligently discuss how they interacted with each other. But the direction of modern discourse seems to indicate the opposite effect. Greg Costikyan wrote "I Have No Words and I Must Design" in 2002 about this exact problem. If he had no words to design with, we may end up with only one, which isn't a much better situation (Costikyan, 2002).

\section{MISCONCEPTIONS AND MISTAKES}

Although MDA is a victim of misinterpretation, I argue that it is also a perpetrator. I do not attack developers/academics/players for misinterpreting MDA out of faith in the framework. Rather, I believe that MDA cannot be treated as a truth of game design, and that we need to consider it along with other approaches. However, we cannot teach students how to deconstruct MDA if they did not understand MDA in the first place.

One of MDA's arguments is that designers experience games from mechanics to dynamics to aesthetics, whereas players experience games from aesthetics to dynamics to mechanics. The terms of mechanics, dynamics, and aesthetics are insightful and valuable. However, I believe that the illustrated progression from one to the next is not only false, but also a reason why the words have become so severely misinterpreted.

Players who want to talk about games in a more intelligent manner will try to use more advanced language, which from this perspective, is the word "mechanics." Anonymous could have written "Kushala Daora beat me and I felt weak and helpless" and that would be an illustration of game aesthetics, but that's 
not how humans express frustration. Likewise, designers who want to appeal to players will use the same language that they use, as seen in Sahlin's GDC talk about empathy as a game mechanic.

We have ended up in a situation where we use the word "mechanics" far too often, and the word "aesthetics" far too rarely. It doesn't help that the word "aesthetic" is already commonly used to refer to artistic quality, which causes people to think that "game aesthetics" means "game art." I believe that the aesthetics are the most important part, and that we must not neglect the value of this term.

\subsection{Players: From Mechanics to Aesthetics}

Hunicke et al. state that "From the player's perspective, aesthetics set the tone, which is born out in observable dynamics and eventually, operable mechanics."

On the contrary, players need to first learn the mechanics and then the dynamics in order to properly appreciate the aesthetics. For example, let us examine chess. The mechanics of chess cover the core rules and the movement for each piece. The dynamics of chess illustrate different strategies, openings, counterattacks, sieges, and all the other types of events that can happen during play. The aesthetics represent the final experience: not only the joy of winning or the sadness of defeat, but also the cleverness of a tricky move, or the bravery of a reckless assault, or the desperation of an unlikely plan.

But when a player first sits down at the chess board, they cannot experience these emotions directly. They cannot be told to feel clever, or brave, or desperate, or joyful or sad. Those emotions need to be earned through gameplay. If the player does not know the rules, then they are not responsible for their actions. And if they are not responsible for their actions, they will not have an emotional attachment. Imagine a player who loses because they do not know the rules. Such a player will not feel disappointed: they will only feel bored. Thus, it makes more sense to say that players experience games from mechanics to dynamics to aesthetics: the complete opposite of what Hunicke et al. described.

The original players-from-aesthetics-to-mechanics position can be understood as a product of its time. MDA was first publicized in 2004, around the period of the ludology vs narratology debate (Aarseth, 2012). This was a period when mainstream AAA games operated primarily through cutscenes, and the indie market with more experimental narrative formats was still growing. Cutscenes can be interpreted as a shortcut to aesthetics which bypasses mechanics and dynamics (Klevjer, 2002). If the player watches enough cutscenes of their character being powerful, eventually they will feel powerful too despite never touching a button. In this context, it is understandable that Hunicke et al. said that aesthetics set the tone.

But today, long after ludology vs narratology, the field of game development has generally settled into the agreement that players are an important part of their own experience. We are seeing more and more games, AAA games even, which are breaking away from the strict cutscene-gameplay-cutscene-gameplay rhythm. Clint Hocking's work on ludonarrative dissonance (Hocking, 2007) has illustrated the importance of guiding players through mechanics to dynamics to aesthetics, rather than just forcing an aesthetic directly. The IMP framework (Elson et al, 2014) is better suited to understand how cutscenes and other external forces influence the experience outside of the MDA loop.

\subsection{Designers: From Aesthetics to Mechanics}

Hunicke et al. state that "From the designer's perspective, the mechanics give rise to dynamic system behavior, which in turn leads to particular aesthetic experiences."

This progression from mechanics to dynamics to aesthetics can also be seen as a product of its time, although the argument is weaker. Modern approaches to game design have shown the importance of working backwards from a strong aesthetic goal. Matt Thorson, creator of Towerfall and Celeste described his process in a GDC talk in 2018 (Thorson, 2018). He starts with the experience that he wants players to have and then iterates his levels until they properly evoke the intended reaction. Each mechanic in Celeste such as dashing or climbing up walls is reverse-derived from the final aesthetic experience.

However, this was a popular view even around the 2004 period. Tracy Fullerton's book "Game Design Workshop" quickly emphasizes that the first thing a designer should do is set "player experience goals": the type of experience that players will have during the game, or in other words, aesthetics (Fullerton, 2004). This is mirrored in Jesse Schell's "Art of Game Design," where the very second chapter is titled "The Designer Creates An Experience" (Schell, 2008). Even outside of games, we can see the same kind of division between aesthetics/experiences and mechanics/handicraft in Scott McCloud's "Understanding Comics", where out of six steps, the idea is first and the form is second (McCloud, 1993). All of these established works of knowledge focus on the designer's ability to conceptualize a central vision and lay out the path carefully and deliberately. 
Hunicke et al.'s argument, that designers start with mechanics which lead to dynamics which lead to aesthetics, seems haphazard in comparison. Is the designer supposed to throw together a bunch of mechanics with no plan or direction and just hope that it ends up being fun? There are several prominent modern designers who are exploring that exact question. Frank Lantz casts doubt on "the iconic image of the designer - smart, confident, sophisticated, stylish, informed" in his post "Against Design", and argues that perhaps we should say that games are discovered or composed rather than designed (Lantz, 2015).

This perspective exists because it is built on top of the previous one. There cannot be an "Against Design" if there is not a "Design" in the first place. Once we realize the limits of our ability to build aesthetics, we can come back to the mechanics-first approach. But starting with mechanics from the very beginning is hardly designing: it is only throwing a game together and hoping it sticks (Pulsipher, 2016).

Naturally, every game production has a different process: some start with aesthetics, some start with mechanics, some with a different approach altogether. However, when Hunicke et al. propose that designers start with mechanics, they don't acknowledge this full range of possibilities. They would not have been able to do so in a short workshop paper, but unfortunately that short workshop paper seems to have developed more traction than expected.

\section{CONCLUSION}

MDA has been one of the most prominent game frameworks in not only industry and academia, but also player communities. We need to properly assess the impact of MDA in order to teach the next generation of game designers how to use it more effectively. In programming, we call this effect a "tech debt," when a whole system is built on top of a piece of outdated legacy code. Removing or refactoring that code could end up sending the whole system crashing down, but then you would be able to rebuild it stronger than before. The burden of handling this tech debt should fall to university teachers, who are in the best position to pinpoint this problem and turn it into a learning opportunity. MDA should be taught as one type of approach, rather than as an incontrovertible truth. Educators can use other models such as SSM (Grip, 2017) or DDE (Walk, 2017) as juxtapositions to better understand MDA and its relation to game design.

\section{REFERENCES}

Aarseth, E. (2012). A narrative theory of games. In Proceedings of the international conference on the foundations of digital Games. ACM, 129-133.

$\begin{array}{llllllll}\text { Anonymous. } & \text { (2018). } & \text { Kushala } & \text { Daora } & - & \text { Monster } & \text { Hunter } & \text { World. }\end{array}$ https://monsterhunterworld.wiki.fextralife.com/Kushala+Daora

Chen, J. (2006). Flow In Games. Master's thesis. University of Southern California.

Costikyan, G. (2002). I Have No Words And I Must Design. The game design reader: A rules of play anthology (2005).

Elson, M., Breuer, J., Ivory, J.D., \& Quandt, T. (2014). More Than Stories With Buttons: Narrative, Mechanics, and Context as Determinants of Player Experience in Digital Games. Journal of Communication 64, 3 (2014),521-542.

Fullerton, T. (2004). Game Design Workshop: A Playcentric Approach To Creating Innovative Games. CRC Press.

Grip, T. 2017. The SSM Framework of Game Design. Blog.

Hocking, C. (2007). Ludonarrative Dissonance https://clicknothing.typepad.com/click_nothing/2007/10/ludonarrative-d.html

Hunicke, R., LeBlanc, M., \& Zubek, R. (2004). MDA: A formal approach to game design and game research. In Proceedings of the AAAI Workshop on Challenges in Game AI, Vol. 4.

Klevjer, R. (2002). In Defense of Cutscenes. In CGDC Conf.

Koster, R. (2003). A Theory of Fun for Game Design. O'Reilly Media.

Lantz, F. (2015). Against Design. http://gamedesignadvance.com/?p=2930cpage $=1$

McCloud, S. (1993). Understanding Comics: The Invisible Art. Tundra Publishing.

Sahlin, M. (2017). Unravel - Using Empathy as a Game Mechanic. https://www.gdcvault.com/play/1024661/-UnravelUsing-Empathy-as.

Schell, J. (2008). Art of Game Design: A Book of Lenses. CRC Press.

Thorson, M. (2018). Level Design Workshop: Designing Celeste. In GDC.

Pulsipher, L. (2016). Are you designing a game, or throwing one together? You can't design a game as though you were playing a video game. Gamasutra.

Walk et al. (2017). Design, Dynamics, Experience (DDE): An Advancement of the MDA Framework for Game Design in Game Dynamics. Best Practices in Procedural and Dynamic Game Content Generation. 